\title{
A busca da autonomia feminina por meio do Programa Teresa DE Benguela do Instituto Federal de Mato Grosso
}

\author{
THE SEARCH FOR FEMALE AUTONOMY THROUGH THE TERESA DE BENGUELA PROGRAM \\ OF THE FEDERAL INSTITUTE OF MATO GROSSO
}

LA BÚSQUEDA DE LA AUTONOMÍA FEMENINA A TRAVÉS DEL PROGRAMA TERESA DE BENGUELA DEL INSTITUTO FEDERAL DE MATO GROSSO

\section{Joelias Silva Pinto Júnior (iD) 9}

Mestre em Computação (UFF)

Professor no Instituto Federal de

Mato Grosso (IFMT)

joelias.junior@ifmt.edu.br

\section{Silvani Aparecida dos Santos Campos (iD) 9}

Tecnóloga em Gestão Pública silvanisantoscampos.ssc@gmail.co $\underline{\mathrm{m}}$

\section{João Luis Binde

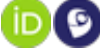

Doutor em Ciência Política (UFPE)

Professor no Instituto Federal de Mato Grosso (IFMT) joao.binde@bag.ifmt.edu.br

\begin{abstract}
Resumo
O Programa Teresa de Benguela eleva a renda de mulheres em situação de vulnerabilidade por meio do empreendedorismo. Este artigo faz uma análise sobre a efetividade do Programa como uma política pública reparadora, a partir do ponto de vista de 144 alunas dos cursos desenvolvidos no Programa, no período de três anos, entre 2017 a 2019, nos campi do IFMT, que executaram projetos do Teresa de Benguela. Utilizou-se revisão sistemática por meio da análise de documentos institucionais e de bibliografias sobre as temáticas de empoderamento feminino, geração de renda e políticas públicas de promoção de renda e superação de situação de vulnerabilidade; e, também, realizaramse entrevistas com estudantes, nas quais foram analisadas as respostas do questionário que avaliou a eficácia, a efetividade e a satisfação com o Programa. Observou-se que as participantes obtiveram elevada satisfação com os conhecimentos adquiridos, com a qualidade dos professores e com os produtos e serviços desenvolvidos no curso. O Programa também demonstrou contribuir para a promoção do empoderamento e autonomia das mulheres atendidas, pois estas se sentiram motivadas e aptas a criar e aplicar os seus conhecimentos. Concluiu-se que o Programa é efetivo para a transformação de vidas femininas. Palavras-chave: Vulnerabilidade. Mulheres. Empoderamento Feminino. Igualdade de Gênero. Promoção de Renda.
\end{abstract}

Recebido em: 7 de outubro de 2021.

Aprovado em: 3 de dezembro de 2021.

Como citar esse artigo (ABNT):

PINTO JÚNIOR, Joelias Silva; CAMPOS, Silvani Aparecida dos Santos; BINDE, João Luis. A busca da autonomia feminina por meio do Programa Teresa de Benguela do Instituto Federal de Mato Grosso. Revista Prática Docente, v. 6, n. 3, e100, 2021. http://doi.org/10.23926/RPD.2021.v6.n3.e100.id1237 


\begin{abstract}
The Teresa de Benguela Program raises the income of women in vulnerable situations through entrepreneurship. This paper analyzes the effectiveness of the Program as a supportive public policy, from the point of view of 144 students from courses developed in the Program, over a period of three years, between 2017 and 2019, on IFMT campuses, who carried out projects of Teresa de Benguela. A systematic review was done through the analysis of institutional documents and bibliographies on the themes of female empowerment, income generation and public policies to promote income and overcome situations of vulnerability; and, also, interviews were carried out with students, in which the answers to the questionnaire that evaluated the efficacy, effectiveness and satisfaction with the Program were analyzed. We observed that the participants obtained high satisfaction with the acquired knowledge, with the quality of the professors and with the products and services developed in the course. The Program also demonstrated that it contributed to promoting the empowerment and autonomy of the women attended, as they felt motivated and able to create and apply their knowledge. It was concluded that the Program is effective in transforming women's lives.
\end{abstract}

Keywords: Vulnerability. Women. Women's Empowerment. Gender Equality. Income Rising.

\title{
Resumen
}

El Programa Teresa de Benguela aumenta los ingresos de mujeres en situación de vulnerabilidad a través del emprendimiento. Este artículo analiza la efectividad del Programa como política pública correctiva, desde el punto de vista de 144 estudiantes de los cursos desarrollados en el Programa, durante un período de tres años, entre 2017 y 2019, en las instalaciones del IFMT, quienes realizaron proyectos de Teresa de Benguela. Se utilizó una revisión sistemática mediante el análisis de documentos institucionales y bibliografías sobre los temas de empoderamiento femenino, generación de ingresos y políticas públicas para promover ingresos y superar situaciones de vulnerabilidad; y, también, se realizaron entrevistas a estudiantes, en las que se analizaron las respuestas al cuestionario que evaluaba la eficiencia, efectividad y satisfacción con el Programa. Se observó que los participantes obtuvieron alta satisfacción con los conocimientos adquiridos, con la calidad de los profesores y con los productos y servicios desarrollados en el curso. El Programa también demostró que contribuyó a promover el empoderamiento y la autonomía de las mujeres atendidas, ya que se sintieron motivadas y capaces de crear y aplicar sus conocimientos. Se concluyó que el Programa es efectivo para transformar la vida de las mujeres.

Palabras clave: Vulnerabilidad. Mujeres. Empoderamiento femenino. Igualdad de género. Promoción de ingresos. 


\section{INTRODUÇÃo}

Ao longo da história, a mulher construiu sua independência em diversos âmbitos desde o social até o econômico (BORGES, 2013). No Brasil, em 1879, conquistou o direito de ter acesso às faculdades; em 1910, foi criado o primeiro partido feminino; e, em 1932, ela conquistou o direito ao voto. Essa postura enfrenta o papel secundário que, no passado, foi designado à mulher como subordinada na sociedade. Foram séculos de condicionamento ao espaço privado do lar em razão de um modelo preestabelecido de família patriarcal, o que a tornou dependente financeiramente do marido e fez com que a sociedade a enxergasse como improdutiva, por não gerar renda. Esse modelo de mulher doméstica foi internalizado socialmente passando a determinar a identidade feminina (BORGES, 2013).

Para Hall (1999), a identidade não é definida de maneira biológica, mas, sim, por meio da história, porque o sujeito assume diferentes identidades em diferentes momentos de modo que a nossa identidade está sempre em constante mudança. Portanto, a identificação está condicionada à forma como se é analisado, ou seja, é construída e modificada de maneira contínua.

A subordinação feminina é, pois, uma construção social de valores patriarcais que atravessaram os tempos e deixaram sua marca na atualidade. As distorções de concepções a respeito do corpo da mulher e de suas subjetividades são reflexos inegáveis dessa marca (BORIS e CESÍDIO, 2007), fatores que contribuíram para sua invisibilidade, para o seu silenciamento, assim como para o tardio reconhecimento e exercício dos seus direitos. Embora existam direitos assegurados de maneira legal, ainda assim, a sociedade impôs à mulher uma cadeia de restrições que dificultou e ainda dificulta a plena conquista da autonomia.

No entanto, o cenário atual é de mudança, o público feminino se empenha em reescrever a sua história e a criação de políticas públicas que auxiliam nesse processo têm sido uma peça indispensável na construção desse novo cenário (BANDEIRA, 2005). Assim, compreender a importância do empoderamento por intermédio da promoção de políticas sociais para a autonomia feminina é fundamental para a conquista efetiva da igualdade de gênero. $\mathrm{O}$ termo empoderamento já é um protagonista no campo das políticas sociais (GOHN, 2004) e trouxe um novo olhar do Estado em relação à mulher. Esse novo olhar tem contribuído de maneira significativa tanto para a sua autossuficiência como também para mudanças de paradigmas na sua rotina, proporcionando a elas maior autonomia e envolvimento social. 
Segundo Romano (2002), o empoderamento traz o foco para as pessoas em vulnerabilidade socioeconômica, possibilitando a superação de suas limitações e sua independência. Nesse sentido, o empoderamento das mulheres por meio de políticas públicas, pode contribuir para a independência financeira e moral delas. Além disso, para Heredia e Cintrão (2006), tais políticas estimulam e promovem oportunidades para elas equipararem o poder tanto no meio privado quanto no público.

Nessa perspectiva, o Programa Teresa de Benguela, uma das políticas públicas voltadas para a promoção de renda, tem sido uma iniciativa para o empoderamento e autossuficiência de mulheres no Estado de Mato Grosso. Criado em 2017, por meio da Ativa Incubadora de Empresas do Instituto Federal de Mato Grosso, o Programa busca criar produtos e serviços liderados por mulheres, de maneira a combater a desigualdade de gênero e contribuir para o empoderamento feminino e para a evolução humana.

O Programa Teresa de Benguela busca cumprir um importante papel como política pública reparadora, porque, ao capacitar mulheres para conhecimentos profissionais específicos, estimula e colabora para a emancipação delas por meio da educação, capacitação e da elevação de renda, possibilitando a elas maior poder de decisão, maior capacidade de fazer escolhas e, sobretudo, maior autonomia. O Programa tornou-se um forte aliado para a inclusão de mulheres em situação de vulnerabilidade no mercado de trabalho por meio do empreendedorismo, cumprindo seu papel social de apoio a elas, pois todos os cursos são permeados de discussões de gênero, empoderamento e autoconfiança.

Desse modo, esta pesquisa teve como objetivo analisar a efetividade do Programa Teresa de Benguela como política pública reparadora no processo de empoderamento e autonomia feminina. Para isso, o estudo analisou dados inéditos, entre o período de 2017 a 2019, sobre a avaliação de 144 estudantes egressas dos campi do IFMT que executaram os Projetos do Teresa de Benguela nesse período.

\section{REFERENCIAL TEÓRICO}

\subsection{EMPODERAMENTO FEMININO}

Em conformidade com o Dicionário de Língua Portuguesa Aurélio, o neologismo "empoderamento" é o ato ou efeito de produzir conscientização tanto social quanto individual, é a ação de promover a autonomia de classes menos favorecidas, é o indivíduo ter domínio e capacidade de tomar suas próprias decisões e gerenciar sua própria vida (FERREIRA, 2019). 
Para Horochovski e Meirelles (2007), o empoderamento, do ponto de vista de independência, é o processo pelo qual a sociedade adquire o poder de tomada de decisão e a capacidade de fazer suas próprias escolhas. Empoderamento é dar voz e visibilidade tanto para os indivíduos como também para instituições carentes da adequada expressão e visibilidade.

A partir desse ponto de vista de empoderamento, o governo e as instituições estão sujeitos à responsabilização social, aumentando o poder social no controle de seus próprios assuntos (FRIEDMANN, 1996), e assim, a reequilibrar a estrutura de poder na sociedade. Dessa forma, o governo visa construir um processo de conscientização que impulsione grupos e comunidades na construção de sua autonomia e redução das desigualdades.

Para Lisboa (2008), o empoderamento da mulher é o novo conceito de poder nas relações de gênero. De modo mais otimista, o empoderamento feminino está construindo novos meios de tomada de decisão e assumindo formas mais democráticas e responsabilidades compartilhadas, destacando-se como peça chave para a conquista da igualdade de gênero, um desafio para os ambientes familiares e as relações patriarcais (COSTA, 2000).

Atualmente, é comum a utilização do termo empoderamento para definir ações coletivas, nas lutas e movimentos sociais de mulheres, negros e homossexuais. Conforme Sardenberg destaca:

De fato, tem-se tornado comum, tanto no discurso acadêmico, quanto de órgãos governamentais e não governamentais - ou mesmo no próprio movimento de mulheres - falar-se do empoderamento de mulheres, sobretudo no contexto do discurso sobre gênero e desenvolvimento (SARDENBERG,2006, p.1).

Segundo Colling (2004), historicamente a mulher vem sendo tratada como inferior e submissa ao homem, desde as relações familiares até as de trabalho. E esse estado de submissão e inferioridade está impregnado na sociedade. No contexto contemporâneo, Nogueira (2001) esclarece que o feminismo é entendido como um movimento social que busca equilibrar a balança da justiça, dando direitos iguais para homens e mulheres.

Do ponto de vista feminista, o empoderamento é o processo de conquista da autossuficiência, da autodeterminação. É a libertação da opressão de gênero e da dominação patriarcal. O principal objetivo do empoderamento feminino é que a mulher assuma o controle sobre o seu próprio corpo, sobre sua própria vida (SARDENBERG, 2006). Conforme afirma Costa:

O empoderamento das mulheres representa um desafio às relações patriarcais, em especial dentro da família, ao poder dominante do homem e à manutenção dos seus privilégios de gênero. Significa uma mudança na dominação tradicional dos homens sobre as mulheres, garantindo-lhes a autonomia no que se refere ao controle dos seus 
corpos, da sua sexualidade, do seu direito de ir e vir, bem como um rechaço ao abuso físico e a violação sem castigo, o abandono e as decisões unilaterais masculinas que afetam a toda a família (COSTA, 2000, p. 9).

Organizações feministas ou de afinidade com essa temática têm ganhado destaque nas linhas de frente da promoção do empoderamento feminino. Elas são facilitadoras no processo de desenvolvimento de ações mobilizadoras e na criação de consciência crítica. Diante dessa perspectiva, e embora ainda permaneçam visíveis as desigualdades entre os gêneros, em conformidade com os dados do Instituto Brasileiro de Geografia e Estatística (IBGE), no Brasil, o rendimento mensal médio do público feminino corresponde a $76 \%$ do masculino, o equivalente a $\mathrm{R} \$ 1764,00$ para as mulheres e $\mathrm{R} \$ 2306,00$ para os homens (IBGE, 2018).

No entanto, há evidências de que o trabalho feminino vem se profissionalizando, diversificando e ocupando progressivamente espaço e importância no mercado de trabalho, como nos mostram os dados do Instituto Nacional de Estudos e Pesquisas Educacionais Anísio Teixeira (INEP). O público feminino é maioria na educação profissional e nos cursos de graduação, fatores que têm contribuído para o crescente aumento de empreendimentos liderados por mulheres (INEP, 2020). Segundo dados do Serviço Brasileiro de Apoio à Micro e Pequenas Empresas (SEBRAE), 43\% dos lares brasileiros são chefiados por mulheres donas do próprio negócio, sendo esse fato o responsável pelo Brasil ocupar no ano de 2018 o $7^{\circ}$ lugar no ranking mundial de empreendedores iniciais (SEBRAE, 2019). Melo e Lopes (2013) acreditam que essas mudanças são sinais do empoderamento das mulheres em termos gerais.

A Declaração da Plataforma de Ação de Pequim (PAP), assinada no ano 1995, foi um documento designado por meio da IV Conferência Mundial das Nações Unidas sobre Mulheres, com o propósito de combater a desigualdade de gênero. Nessa declaração os governos adotaram e se comprometeram a colocar em prática a Plataforma de Pequim de forma a garantir que a Perspectiva de Igualdade entre homens e mulheres seja refletida em todas as suas Políticas e Programas.

Nesse seguimento, a Organização das Nações Unidas (ONU) com a intenção de promover o empoderamento feminino, criou, em 2010, a ONU Mulheres, entidade das Nações Unidas para Igualdade de Gênero e Empoderamento das Mulheres, cujo principal objetivo é garantir os direitos humanos de todas as mulheres do mundo e defender os compromissos internacionais assumidos pelos Estados-Membros da ONU com os direitos humanos das mulheres (ONU, 2020). 
A partir dessa perspectiva de empoderamento, a ONU Mulheres criou com o Pacto Global da ONU (ONU MULHERES, 2010) uma lista com sete princípios básicos de empoderamento feminino no âmbito social e profissional. São eles:

1. Estabelecer liderança corporativa sensível à igualdade de gênero, no mais alto nível.

2. Tratar todas as mulheres e homens de forma justa no trabalho, respeitando e apoiando os direitos humanos e a não-discriminação.

3. Garantir a saúde, segurança e bem-estar de todas as mulheres e homens que trabalham na empresa.

4. Promover educação, capacitação e desenvolvimento profissional para as mulheres.

5. Apoiar empreendedorismo de mulheres e promover políticas de empoderamento das mulheres através das cadeias de suprimentos e marketing.

6. Promover a igualdade de gênero através de iniciativas voltadas à comunidade e ao ativismo social.

7. Medir, documentar e publicar os progressos da empresa na promoção da igualdade de gênero.

Ações como essa da ONU também se mostraram como interesse de órgãos governamentais brasileiros, os quais também criaram alguns Programas, tais como: Mulheres Mil, Mulheres Inovadoras, Bolsa Família, Rede Brasil Mulher, Teresa de Benguela e muitos outros. As políticas sociais incentivadas pelo governo têm auxiliado e fomentado mudanças nos padrões e na cultura da sociedade (CASTRO, 2012).

\subsection{EMPREENDEDORISMO}

O termo empreendedor é derivado da palavra francesa entrepreneur, que diz respeito ao indivíduo que tem coragem de assumir riscos (FERREIRA et al., 2014). Além disto, no conceito de empreendedor contemporâneo, ele também deve dispôr de infraestrutura (física ou virtual), tecnologia, mercado, finanças e talentos (PINTO JUNIOR et al., 2021). Apesar de o empreendedorismo ser bem aceito pela sociedade, ele ainda é considerado uma prática de mercado tradicionalmente masculina (MACHADO, 2012). Isso ocorre, porque a sociedade já tem um modelo pré-estabelecido de mulher doméstica e, portanto, funções que são típicas do público feminino.

Durante muito tempo o ato de empreender era restrito apenas aos homens, mas, aos poucos, as mulheres foram conquistando o espaço delas no ramo do empreendedorismo e, atualmente, muitas já são protagonistas da sua independência por intermédio dos próprios empreendimentos. No Brasil, de acordo com Macêdo et al. (2004), as empreendedoras inovam também na cultura organizacional, ao se colocarem como um contraponto à exclusão das mulheres do processo sucessório de empresas familiares. 
Nessa perspectiva de compreensão da importância do ato de empreender, o público feminino ganhou destaque nos últimos anos como força motora para o progresso e evolução da economia de muitos países que estão em desenvolvimento (NATIVIDADE, 2009). A partir desse contexto de mudanças culturais, a participação feminina vem sendo modificada na sociedade e no mercado de trabalho.

As mulheres vêm ganhando visibilidade e um papel de destaque no universo do empreendedorismo brasileiro. Pesquisas conduzidas pelo SEBRAE, como a Global Entrepreneurship Monitor (GEM) e o Anuário do Trabalho nos Pequenos Negócios, mostram que, desde 2017, as mulheres superaram os homens na abertura de empresas e já são maioria entre os trabalhadores com carteira assinada nos pequenos negócios (ONU MULHERES, 2020). A finalidade é compartilhar poder às mulheres para que participem de forma plena da vida econômica em todos os setores e em todos os níveis da economia brasileira.

\subsection{AÇõES PARA PROMOÇÃO DE RENDA DE PESSOAS EM SITUAÇÃO DE VULNERABILIDADE}

O Instituto de Pesquisa Econômica Aplicada (IPEA) revela que a criação de programas federais de transferência de renda foi uma das mais importantes novidades ocorridas na política social brasileira entre o final dos anos 1990 e o início do século XXI (IPEA, 2006).

Nessa linha de pensamento, Marinho et al. (2011) destacam que os programas de assistência do governo são os agentes de maior resultado distributivo e o que melhor identifica a população carente. Esses programas, conforme afirma Sacchet (2015, p.316), entregam índices elevados de capital social que cooperam para promoção da igualdade política entre homens e mulheres e também para maior igualdade social. Nesse contexto, as políticas públicas reparadoras têm sido a porta de entrada do público feminino no mercado de trabalho. Bruschini et al. (2003, p.62) asseveram que "Nos últimos, elas vêm sendo beneficiadas por um conjunto de normas legais e ações governamentais que tentam promover a igualdade de gênero no trabalho".

A criação de políticas públicas que promovam o empoderamento feminino são medidas de suma importância no combate à desigualdade tanto de gênero quanto social, porque criam ações que dão voz e visibilidade para o público feminino, o que, de acordo com o SEBRAE (2020) tem proporcionado aumento significativo de mulheres empreendedoras no mercado de trabalho.

No trabalho de PINTO JUNIOR et al. (2021a), é possível perceber o importante papel das capacitações promovidas por uma ação de política pública de um Instituto Federal, onde a 
educação empreendedora tomou papel fundamental para auxiliar na superação de vulnerabilidades encontradas nos empreendimentos atendidos.

O Programa Bolsa Família, um dos mais conhecidos Programas brasileiros, é o que mais enfatizou e se destacou no combate e erradicação da pobreza. O Programa tem como principal objetivo garantir uma renda mínima à população mais carente. Outros programas, tais como: o Pró Família e o Panela Cheia, do Estado de Mato Grosso, assim como o PROGER - Programa de Geração de Renda do Governo Federal, em parceria com o Sebrae, contribuem de forma direta para a conquista da autonomia feminina. Esses Programas têm como foco a redução das desigualdades sociais, promovendo cidadania e inclusão social de famílias que se encontram em situação de vulnerabilidade, já que muitas delas são chefiadas por mulheres.

Segundo Perucchi e Beirão (2007), é crescente o número de lares chefiados por mulheres brasileiras e esse novo modelo de família totalmente inverso do modelo familiar patriarcal tem sido desvantajoso para o público feminino, já que o seu papel como mãe dificulta a sua inserção no mercado de trabalho.

\section{Procedimentos do método}

Como metodologia de pesquisa deste trabalho, foi realizada uma revisão sistemática por meio da análise de documentos institucionais e de bibliografias sobre as temáticas de empoderamento feminino, geração de renda e políticas públicas de promoção de renda e superação de situação de vulnerabilidade, utilizando fontes e dados da literatura para evidenciar uma intervenção específica (SAMPAIO e MANCINI, 2007 e GIL, 2002). Também foram realizadas entrevistas com estudantes, a partir das quais se analisaram as respostas do questionário que avaliou a eficácia, a efetividade e a satisfação com o Programa.

As principais bases bibliográficas utilizadas para esta pesquisa foram o Google Acadêmico e a Scielo, utilizando os termos "programas para o empoderamento feminino", "empoderamento de mulheres" e "autonomia feminina".

Para a busca de informações contextualizadas ao Estado de Mato Grosso, e do Governo Federal, foram utilizados os sites www.mt.gov.br e o www.sebrae.com.br para encontrar informações sobre programas de promoção de renda para pessoas carentes.

Em seguida, partiu-se para a análise específica do Programa de Extensão Teresa de Benguela, foco desta pesquisa. Fez-se contato com a gestão do Programa, que disponibilizou alguns documentos importantes, tais como: Editais de seleção de projetos, Resolução $n^{\circ} 046$ de aprovação do regulamento do Programa Teresa de Benguela, Guias de empreendedorismo e 
incubação (Cartilhas) e os dados coletados a partir de um questionário de avaliação do Programa, aplicado entre os anos de 2017, 2018 e 2019.

Nesse questionário desenvolvido pela gestão do Programa, foi utilizada a abordagem quanti-qualitativa, para entender, a partir de números e levantamentos de dados, a opinião, expectativa e sentimento de um determinado grupo de pessoas, com a finalidade de compreender os detalhes e as peculiaridades, o que permitiu maior familiaridade com o problema (MARCONI e LAKATOS 2017, p. 298).

No tocante à escolha das perguntas contidas no questionário, a Gerente da Ativa Incubadora, Léa Morais, explica que se baseou em outros formulários de avaliação de projetos já reconhecidos institucionalmente pelo IFMT, mas que usou, também, de seu conhecimento do Programa, das mulheres atendidas e de suas realidades, para pensar os questionamentos de avaliação. Em suas palavras: "As questões (qualitativas e quantitativas) foram elaboradas a partir da minha percepção extensionista, educacional e do Programa em si” (ATIVA, 2020).

A análise quantitativa foi realizada por meio do levantamento de dados das questões fechadas do questionário que buscou analisar dados demográficos (ex.: idade e número de filhos etc.) e grau de satisfação com o Programa e professores. Já a análise qualitativa foi realizada com questões abertas, que indagavam as experiências e emoções vividas dentro do próprio Programa.

O questionário foi composto por 18 perguntas, divididas em duas partes: a primeira constituída por dados sociodemográficos e ocupacionais; e a segunda, buscando apontar a percepção das participantes sobre o Programa. No Quadro 1, é possível visualizar a distribuição da quantidade de mulheres atendidas pelo Projeto, bem como as que responderam aos questionários, por curso e campus de execução do projeto.

Quadro 1 - Número de participantes por curso e por Campus do Programa Teresa de Benguela no período de 2017,2018 e 2019

\begin{tabular}{|l|l|c|}
\hline \multicolumn{1}{|c|}{ Campus } & \multicolumn{1}{c|}{ Curso } & N. de Participantes \\
\hline Rondonópolis & Empreendedorismo (Donas de si) & 18 \\
\hline Tangará da Serra & Empreender para a liberdade & 16 \\
\hline Cáceres & Produtoras do derivado do leite & 23 \\
\hline Cáceres & Preparadora cervejeira artesanal & 20 \\
\hline Sorriso & Pintura em tela & 7 \\
\hline Juína & Curso de vigilante e defesa pessoal & 4 \\
\hline Várzea Grande & Racismo Ambiental & 47 \\
\hline Ponte e Lacerda & Produção de embutidos defumados e cárneos artesanais & 9 \\
\hline
\end{tabular}

Fonte: Elaborado pelos autores com base na pesquisa. 
Para facilitar o processo de análise e discussão dos dados coletados, foi feita a tabulação e tratamento destes e suas respectivas apresentações em gráfico.

\section{Resultados}

Os resultados serão apresentados nesta seção em três segmentos: o primeiro se refere ao perfil das participantes; o segundo, à avaliação das participantes sobre o curso; e o terceiro, ao efeito dos cursos sobre as participantes.

\subsection{Perfil das Participantes}

Em análise, os dados revelam que, nas questões em que se perguntou se conheciam o IFMT, 54,9\% das participantes afirmaram que o conheciam e 40,3\% responderam que não o conheciam e 4,9\% não responderam. Destas, 49,0\% ficaram sabendo por intermédio de amigos e 19,6\% ficaram sabendo pela comunidade local (Figura 1).

Figura 1 - Representação dos resultados referentes à como as participantes do Programa Teresa de Benguela ficaram sabendo dos cursos

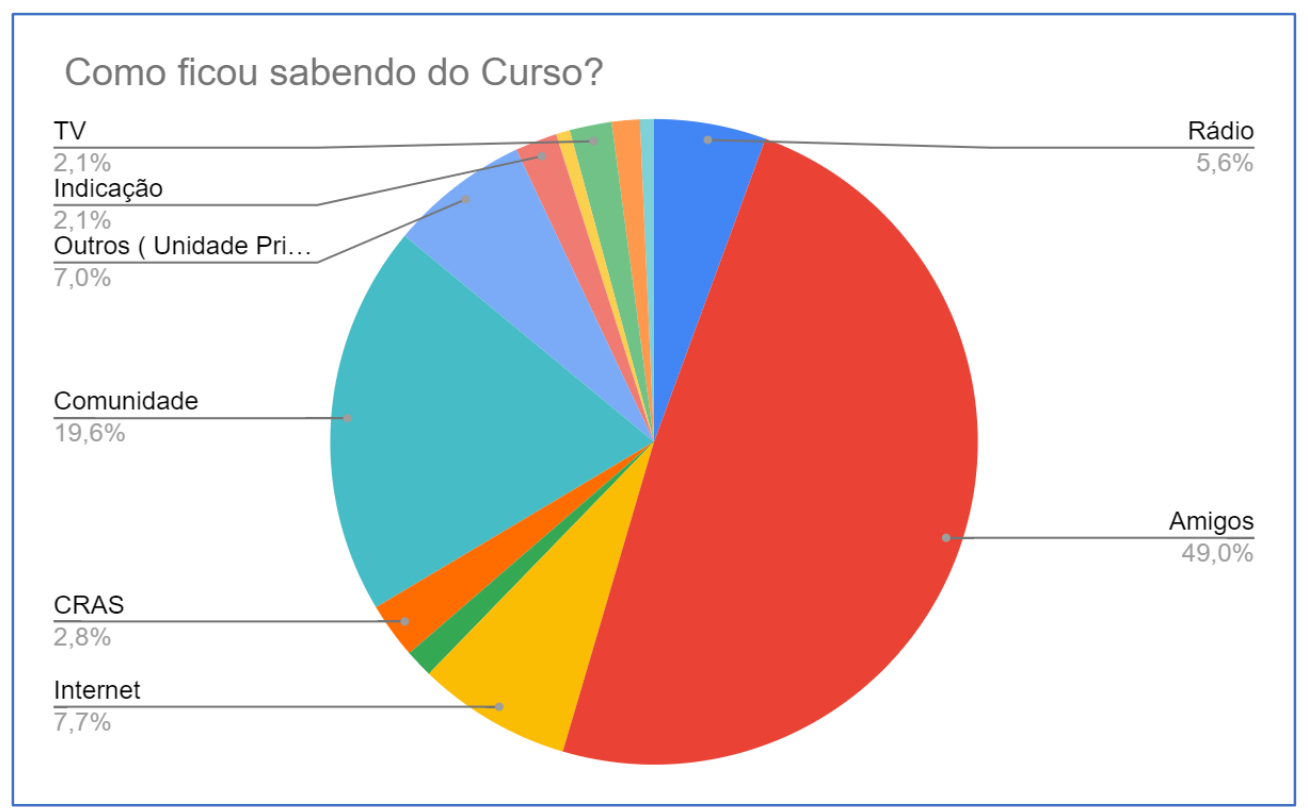

Em relação à idade, 29,4\% tinham de 36 a 45 anos, 20,3\% tinham de 46 a 55 e 17,5\% tinham de 30 a 35 anos (Figura 2). É perceptível que a maior participação está concentrada entre os 30 a 55 anos. 
Figura 2 - Distribuição das participantes do Programa Teresa de Benguela em relação à idade

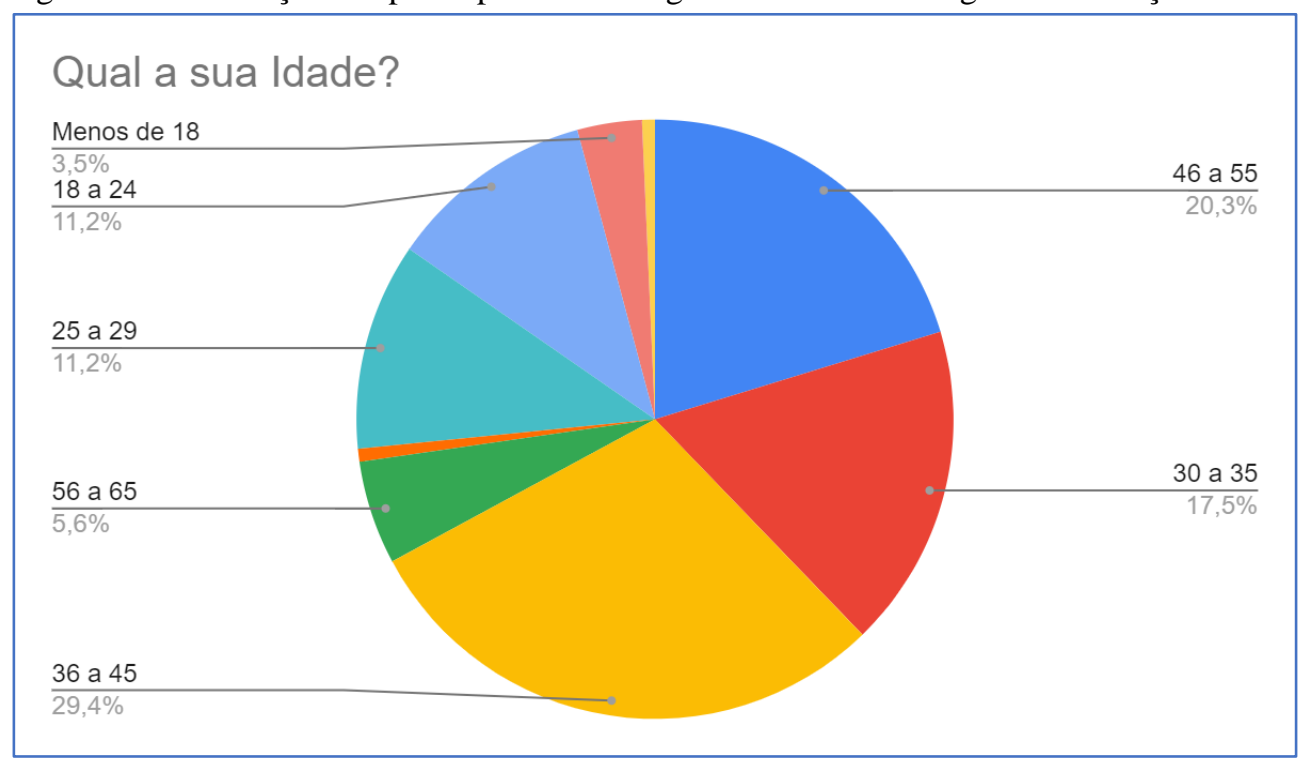

Quanto ao número de filhos, 35,0\% tinham de três a quatro filhos, 32,9\% tinham de um a dois filhos e 24,5\% não tinham nenhum filho (Figura 3). No tocante à quantidade de filhos com menos de 18 anos, 46,9\% não tinham filhos nessa faixa etária, 33,6\% tinham dois ou três filhos com menos de 18 anos e 15,4\% tinham três ou quatro filhos com menos de 18 anos e $3,5 \%$ não responderam.

Figura 3 - Representação dos resultados referentes à quantidade de filhos das participantes do Programa Teresa de Benguela

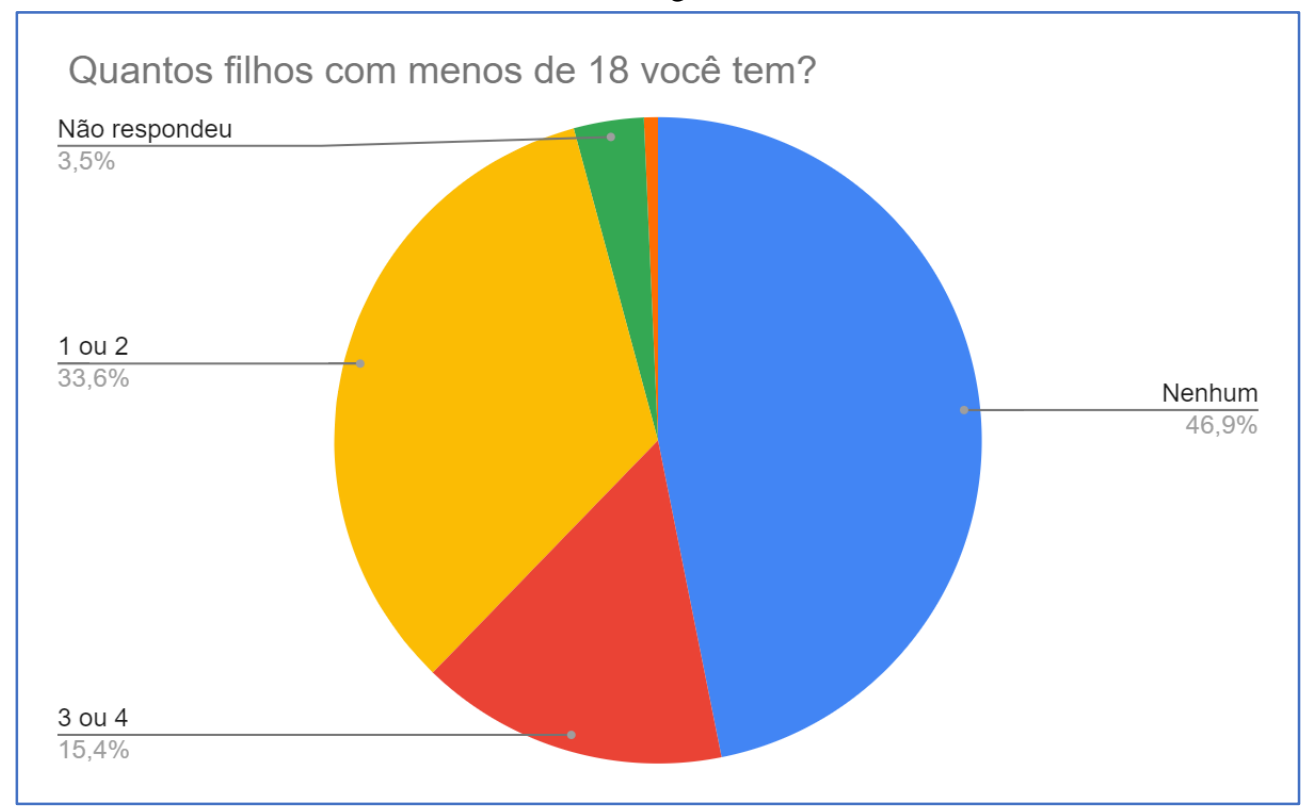

Em relação à contribuição para a renda familiar, $66,7 \%$ das alunas afirmaram contribuir para a renda familiar e 32,6\% informaram não contribuir e 0,7\% não responderam. Destes lares, $55,2 \%$ afirmam que apenas duas pessoas são responsáveis pela renda familiar e 34,3\% afirmam que apenas uma pessoa é responsável pela renda familiar (Figura 4). 
Figura 4 - Representação da quantidade de pessoas que contribuem para a renda familiar das participantes do Programa Teresa de Benguela

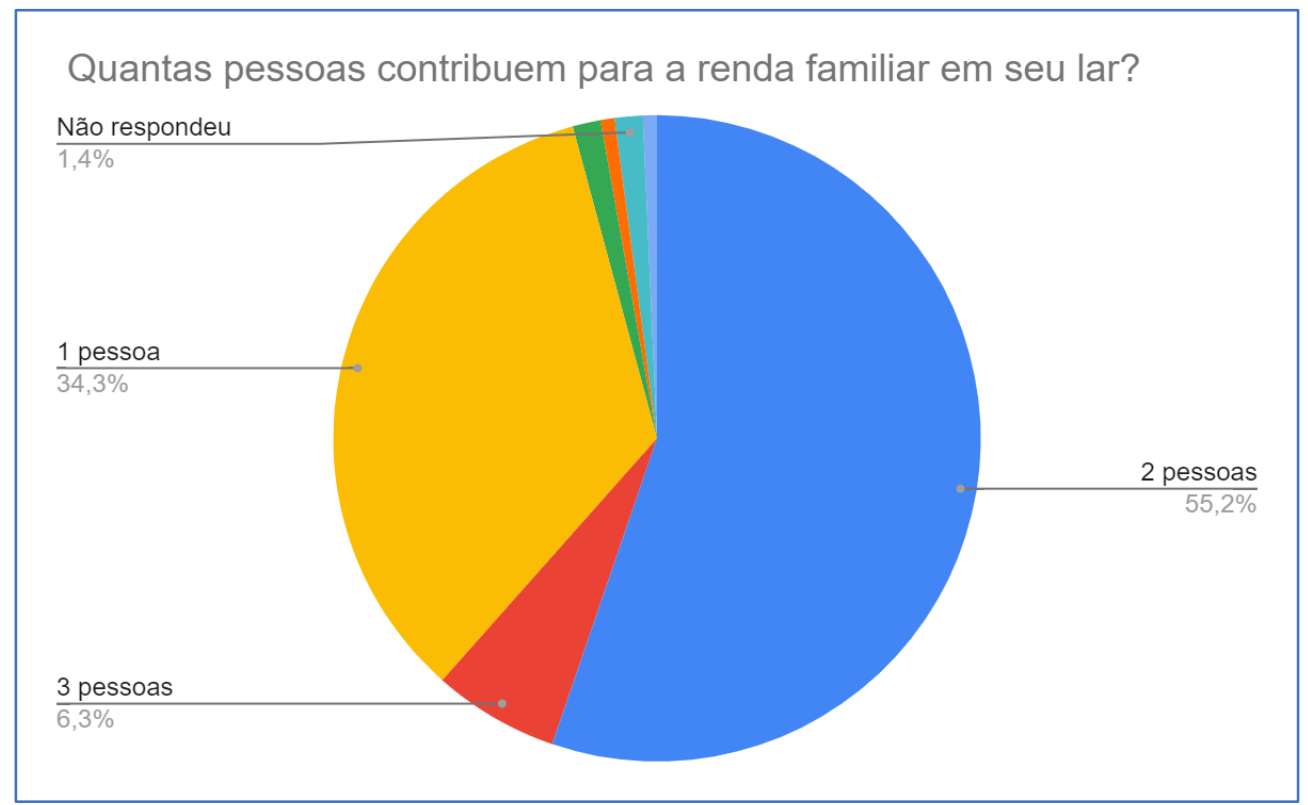

No tocante ao recebimento de auxílio do governo, 54,9\% das alunas afirmam não receber nenhuma assistência do governo e 40,3\% afirmam receber e 4,9\% não responderam. Quando iniciaram o curso, a maioria das participantes, 39,7\%, estava desempregada e 30,5\% estavam trabalhando (Figura 5).

Figura 5 - Representação dos resultados referentes à situação de trabalho que cada participante exercia antes de ingressarem nos cursos do Programa Teresa de Benguela

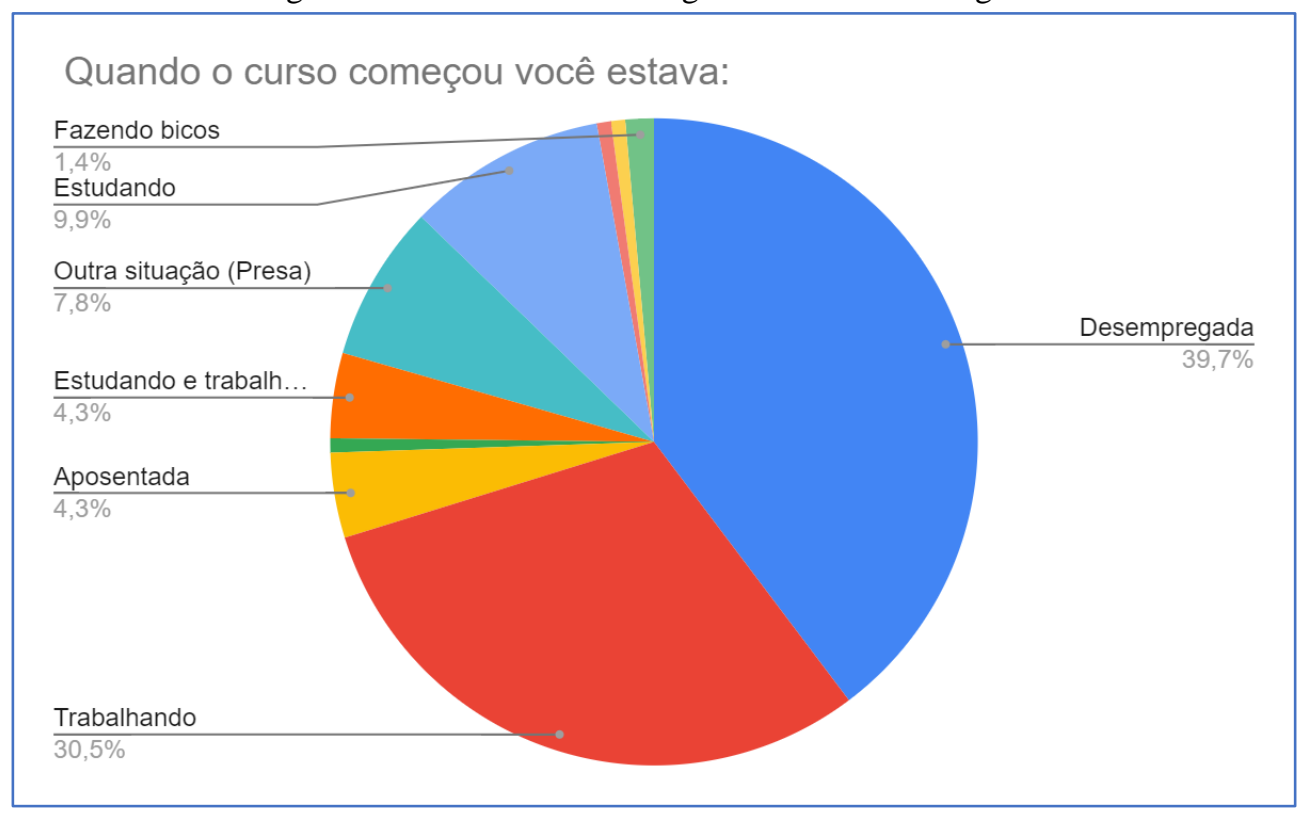

\subsection{AVALIAÇÃo das PaRTiCiPantes SObRe OS CURSOS}

Em relação à satisfação com o conhecimento recebido por meio do Programa Teresa de Benguela, 59,4\% das participantes respondentes disseram estar muito satisfeitas, 35,7\% 
satisfeitas e 4,9\% disseram ser regular. As respostas para Insatisfeito e muito insatisfeito tiveram valores iguais a 0 .

Referente à avaliação dos professores, 62,9\% das participantes disseram estar muito satisfeitas, 18,2\% não responderam, 15,4\% disseram estar satisfeitas, 2,1\% avaliaram como regular e 1,4\% declararam estar muito insatisfeitas com os instrutores.

No quesito avaliação dos produtos e serviços desenvolvidos no curso, 47,6\% disseram estar muito satisfeitas, $42,7 \%$ disseram estar satisfeitas e $6,3 \%$ avaliaram como regular e $2,8 \%$ não responderam.

Em relação a melhorias no curso, os fatores mais citados foram: ter mais aulas presenciais, ter mais aulas práticas e local adequado para as aulas práticas.

\subsection{EFEITO DO CURSO SOBRE AS PARTICIPANTES}

Quanto ao quesito motivação para continuar ou abrir um negócio na área de formação promovida pelo curso, um percentual de $34,0 \%$ das alunas se sente muito motivadas, 33,3\% dizem estar motivadas, $18,8 \%$ não responderam e $13,9 \%$ se sentem regularmente motivadas quanto a produzir e vender o que aprenderam no curso.

No quesito aptidão para aplicação dos conhecimentos adquiridos, 39,6\% disseram estar aptas, 30,6\% disseram estar muito aptas, 19,4\% se sentem regular, 5,6\% se sentem pouco aptas, 3,5 não responderam e 1,4\% afirmaram estar muito pouco aptas para aplicar o conhecimento e melhorar a renda (Figura 6).

Figura 6 - Representação dos resultados referentes à aptidão das participantes do Programa Teresa de Benguela

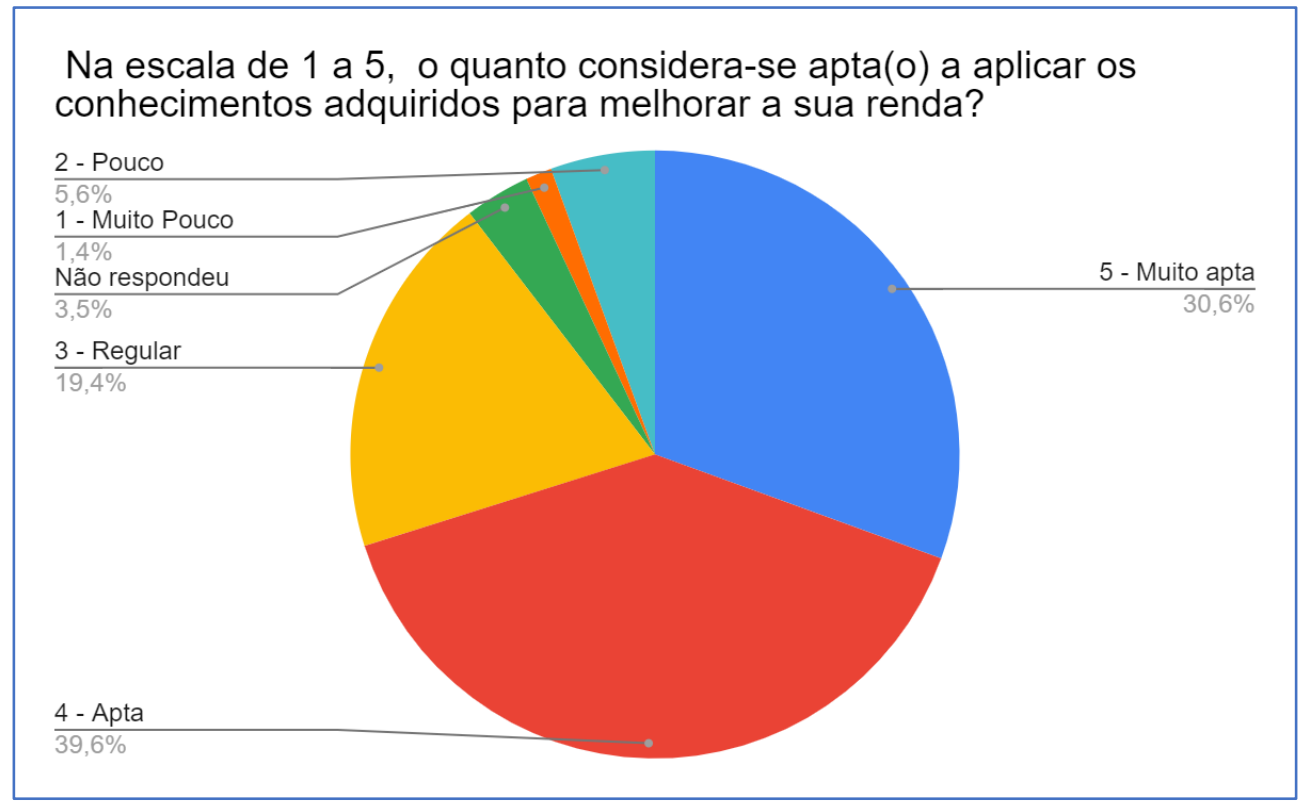


Nas questões abertas, referentes aos sonhos e idealizações das participantes em abrir o seu próprio negócio, a maioria afirmou possuir o desejo de abrir um negócio, sendo os principais ramos o de confeitaria, salão de beleza e loja de roupas. E, por fim, sobre as experiências e momentos marcantes dentro do curso, foram citadas viagens especiais para outros Campi, ter conhecido mulheres corajosas e guerreiras, aprender a fazer bolo, saber que todos os professores eram voluntários, contar a própria história e muitos outros depoimentos. Também, muitos professores foram elogiados.

\section{DiscuSSÃo}

De acordo com a análise referente ao perfil das participantes, é possível constatar que o grupo de maior interesse nos cursos do Programa e que, portanto, revela um perfil mais ávido por estudar o empreendedorismo e a autonomia feminina, são mulheres com idade de 30 a 55 anos, que têm de um a quatro filhos com idade inferior a 18 anos. Muitas dessas mulheres não recebiam nenhum auxílio do governo, estavam desempregadas quando iniciaram o curso e viviam em lares onde de uma a duas pessoas contribuem para a renda familiar e quase $70 \%$ delas eram um desses contribuintes.

Percebe-se, por meio desses dados, a relevância do Programa Teresa de Benguela, porque, ao atingir o público-alvo: as mulheres, oferecendo educação e capacitação para elas, ele contribui de maneira significativa para o desenvolvimento da sua autoestima e elevação da sua renda.

Apesar de os dados revelarem que 54,9\% das participantes conheciam o Instituto Federal de Mato Grosso, uma parcela grande de pessoas, mais de 40\%, afirmou não ter esse conhecimento. Esse é um dado que merece atenção, uma vez que os cursos do Programa são promovidos pela Instituição. Faz-se necessária, portanto, a utilização de meios de divulgação, que consigam atingir com eficácia esse público.

Referente à avaliação das participantes sobre os cursos, conforme mostram os dados, $70 \%$ das alunas afirmaram estar satisfeitas com o conhecimento adquirido, com os professores e com os produtos e serviços desenvolvidos no curso. Isso pode evidenciar que o formato dos cursos ofertados é eficaz e a formação profissional e os produtos oferecidos são de qualidade, o que permite que essas mulheres tenham a chance real para o sucesso na gestão de seus empreendimentos.

No entanto, ocorreram também questionamentos sobre melhorias na infraestrutura, no formato das aulas e na quantidade de aulas práticas, o que evidencia que essas melhorias podem 
influenciar de maneira significativa no aprendizado dessas alunas, haja vista que, para que os cursos sejam de qualidade, é preciso que a infraestrutura, o número de aulas e as aulas práticas sejam adequados ao trabalho que será desenvolvido. Do contrário, ficará possivelmente uma lacuna na formação dos profissionais que o curso visa formar para o mercado de trabalho.

Em relação ao efeito dos cursos sobre as participantes, os dados mostram que mais da metade das participantes se sentem motivadas e aptas para criar e aplicar os produtos e conhecimentos adquiridos. Isso permite concluir que o programa tem sido capaz de gerar resultados positivos para o empoderamento e autonomia dessas mulheres.

Quanto aos sonhos e idealizações das participantes, fica evidente que todas sonham com a sua independência, com sua autonomia, o que torna o Programa Teresa de Benguela, usando a licença de emprestar as palavras já muito usadas em pesquisas, um divisor de águas na vida de cada uma delas, afinal, amplia os seus horizontes de maneira a tornarem reais seus sonhos de chefe dos próprios empreendimentos e da própria vida.

Percebe-se, também, nos relatos de fatos marcantes do curso, que essas mulheres se sentiam felizes em sair do espaço particular para o público, felizes por compartilharem sua história de vida, por perceberem que tinham um espaço em que eram ouvidas e, também, que podiam ouvir as histórias de vida de outras colegas. Aqui, é possível perceber o impacto do Programa Teresa de Benguela para o empoderamento e autonomia dessas mulheres.

O Programa Teresa de Benguela atingiu seu objetivo referente às capacitações, porque, ao promover acesso à educação, trouxe benefícios não só para o empoderamento feminino, mas também tornou possível o sonho de independência daquelas mulheres. Em outras palavras, o Programa cumpriu seu papel como política pública reparadora, ao possibilitar a elas experiência no espaço público, quebra de tabus, conhecimento sobre seus direitos e a possibilidade real de conquistar sua autonomia.

\section{CONSIDERaÇões Finais}

Esta pesquisa objetivou analisar a efetividade do Programa Teresa de Benguela, a partir do ponto de vista de 144 alunas dos cursos desenvolvidos no Programa, no período de três anos. A análise foi feita a partir das respostas dessas alunas em um questionário de avaliação da eficácia, efetividade e satisfação com o Programa. De acordo com seu regulamento, o Programa tem como principal objetivo a elevação de renda por meio da educação e capacitação de mulheres socialmente vulneráveis. 
Inicialmente, foi possível deduzir que o Programa tem desempenhado um papel importante no campo social ao proporcionar capacitação e autonomia ao público feminino que se encontra em situação de vulnerabilidade. Analisando os resultados das pesquisas, foi confirmada essa hipótese: o Programa realmente se mostrou capaz de obter efeitos positivos para a elevação de renda e para o empoderamento feminino.

O programa, além de atingir o seu público-alvo, também obteve resultados satisfatórios nas variáveis relacionadas à elevação da autoestima e na qualidade dos cursos, um fator de suma importância para a promoção da autonomia e para o desenvolvimento social dessas mulheres. Os cursos disponibilizados pelo Programa têm contribuído para a construção da autonomia feminina, inserindo-as na sociedade, elevando a autoestima delas e, o mais importante, motivando-as e dando oportunidade de chefiar os seus próprios empreendimentos, tornando-as mulheres empoderadas.

Como política pública, o Programa tem, sim, conseguido proporcionar ao público feminino melhorias de vida, ou seja, tem possibilitado ao público feminino desempenhar um novo papel na sociedade. Os cursos ofertados têm produzido efeitos positivos sobre a forma como essas mulheres veem o mundo e de como se encaixam nele. No entanto, para a total eficiência dessas ações, torna-se necessária uma maior atenção do Estado nas questões relacionadas aos materiais e à infraestrutura onde serão realizados os cursos. Torna-se fundamental a promoção de ações intergovernamentais que visem desenvolver a total eficácia do Programa.

Desse modo, a sociedade ganha como um todo, com profissionais qualificadas, mulheres motivadas e empoderadas, dispostas a fazer a diferença. Logo, o Programa Teresa de Benguela se posiciona como uma forte ferramenta para a construção da nova imagem da mulher frente à sociedade.

\section{REFERÊNCIAS}

ATIVA, Incubadora de empresas do IFMT. Programa Teresa de Benguela. Disponível em: http://ativa.ifmt.edu.br. Acesso em: 13 jun. 2020.

BANDEIRA, Lourdes. Brasil: fortalecimento da secretaria especial de políticas para as mulheres para avançar na transversalizaçao da perspectiva de gênero nas políticas públicas. In: MELO, Hildete Pereira de; BANDEIRA, Lourdes. A pobreza e as políticas de gênero no Brasil. Santiago de Chile: Unidad Mujer y Desarrollo - Projecto "Governabilidade democrática e igualdade de gênero", 2005. Disponível em: https://repositorio.cepal.org/bitstream/handle/11362/5944/S055322 pt.pdf. Acesso em: 03 set. 2020. 
BORGES, Carolina de Campos. Mudanças nas trajetórias de vida e identidades de mulheres na contemporaneidade. Revista de Psicologia em Estudos, Maringá, v.18, n.1, p.71-81, Jan/Mar, 2013. Disponível em: https://www.scielo.br/pdf/pe/v18n1/v18n1a07.pdf. Acesso em: 28 jun. 2020.

BORIS, Georges Daniel Janja Bloc; CESÍDIO, Mirella de Holanda. Mulher corpo e subjetividade: uma análise desde o patriarcado à contemporaneidade. Revista Mal-Estar e Subjetividade, Fortaleza, v.7, n. 2, 2007. Disponível em: http://pepsic.bvsalud.org/scielo.php?script=sci arttext\&pid=S1518-61482007000200012. Acesso em: 28 jun. 2020.

BRONZO, Carla. Vulnerabilidade, Empoderamento e Proteção Social. Reflexões a partir de experiências latino-americanas. EnANPAD, XXXII, 2008.

BRUSCHINI, Cristina; LOMBARDI, Maria Rosa; MERCADO, Cristiano Miglioranza; RICOLDI, Arlene. Trabalho, renda e políticas sociais: avanços e desafios. In: ONU Mulheres. Leila Linhares Barsted, Jacqueline Pitanguy (Org.). O Progresso das Mulheres no Brasil 2003-2010. Brasília, 2011. Disponível em: http://onumulheres.org.br/wpcontent/themes/vibecom_onu/pdfs/progresso.pdf. Acesso em: set. 2021.

CASTRO, Jorge Abrahão de. Política social e desenvolvimento no Brasil. Revista economia e Sociedade, v. 21, n. spe, Campinas, 2012. Disponível em: https://doi.org/10.1590/S010406182012000400012 . Acesso em: abril 2020.

COLLING, Ana. A construção histórica do feminino e do masculino. In: STREY, Marlene Neves; CABEDA, Sonia Lisboa \& PREHN, Denise Rodrigues (Org.). Gênero e cultura: questões contemporâneas (13-38). Porto Alegre: EDIPUCRS, 2004.

COSTA, Ana Alice. Gênero, poder e empoderamento das mulheres. Núcleo de Estudos, 2000. Disponível em:

http://www.reprolatina.institucional.ws/site/respositorio/materiais_apoio/textos_de_apoio/Ge nero poder e empoderamento das mulheres.pdf. Acesso em: 20 abril 2020.

FERREIRA, Aurélio Buarque de Holanda. Mini Aurélio o dicionário da língua Portuguesa. 8. ed. Curitiba: Ed. Positivo, 2019.

Ferreira, Felipe Leal Alves, Gimenez, Fernando Antônio Prado, \& Augusto, Paulo Otávio Mussi. Empreendedorismo e o Processo de Criação de uma Nova Organização. Iberoamerican Journal of Entrepreneurship and Small Business, 3 (2), 70 93. https://doi.org/10.14211/regepe.v3i2.128

FRIEDMANN, John. Empowerment: Uma Política de Desenvolvimento alternativo. Oeiras: Celta, 1996.

GIL, Antonio Carlos. Como elaborar projetos de pesquisa. 4. ed. São Paulo: Ed. Atlas, 2002.

GOHN, Maria da Glória. Empoderamento e participação da comunidade em políticas sociais. Revista de Saúde e Sociedade, v.13, n. 2, p. 20-31. 2004. https://doi.org/10.1590/S0104$\underline{12902004000200003}$ 
HALL, Stuart. A identidade cultural na pós-modernidade. (Tomas Tadeu da Silva \& Guacira Lopes Louro (Tradução). Rio de Janeiro: Ed. DP \& A. $11^{\circ}$ ed., 1999. Disponível em: https://edisciplinas.usp.br/pluginfile.php/4135505/mod_resource/content/1/A\%20Identidade\% 20Cultural\%20na\%20P\%C3\%B3s-Modernidade\%20-\%20Stuart\%20Hall.pdf. Acesso em: 26 ago.2020.

HEREDIA, Beatriz Maria Alásia de.; CINTRÃO, Rosângela Pezza. Gênero e acesso a políticas públicas no meio rural brasileiro. Revista NERA. Ano 9, n. 8. 28p. Presidente Prudente, Janeiro/Junho de 2006. https://doi.org/10.47946/rnera.v0i8.1443

HOROCHOVSKI, Rodrigo Rossi; MEIRELLES, Giselle. Problematizando o conceito de empoderamento. In: ANAIS DO II SEMINÁRIO NACIONAL MOVIMENTOS SOCIAIS PARTICIPAÇÃO E DEMOCRACIA. UFSC, Florianópolis, 2007.

IBGE. Instituto Brasileiro de Geografia e Estatística. Indicadores Sociais das Mulheres no Brasil. Disponível em: https://educa.ibge.gov.br/jovens/materias-especiais/materiasespeciais/20453-estatisticas-de-genero-indicadores-sociais-das-mulheres-nobrasil.html\#subtitulo-1. Acesso em: 25 jun. 2020.

INEP. Instituto Nacional de Estudos e Pesquisas Educacionais Anísio Teixeira. Mulheres são maioria na educação profissional e nos cursos de graduação. Disponível em: http://inep.gov.br/artigo/-/asset_publisher/B4AQV9zFY7Bv/content/mulheres-sao-maioriana-educacao-profissional-e-nos-cursos-de-graduacao/21206. Acesso em: 25 jun. 2020.

IPEA. Instituto de Pesquisa Econômica Aplicada. TD-1258: A queda recente da desigualdade de renda no Brasil. Disponível em:

http://www.ipea.gov.br/portal/index.php?option=com_content\&id=4822. Acesso em: 16 abril 2020.

LISBOA, Teresa Kleba. O empoderamento como estratégia de inclusão das mulheres nas políticas sociais. Fazendo gênero 8 - Corpo, Violência e Poder. Universidade Federal de Santa Catarina. Florianópolis, 2008. Disponível em:

http://www.wwc2017.eventos.dype.com.br/fg8/sts/ST11/Teresa_Kleba_Lisboa_11.pdf. Acesso em: 03 set. 2021.

MACÊDO, Kátia Barbosa; CAIXETA, Cássia Maria Moura; GUIMARÃES, Daniela Cristina; MACEDO, Goiacira Nascimento Segurado; HERNANDEZ, Janete Capel. O processo sucessório em organizações familiares e a exclusão da mulher. Psicologia \& Sociedade, v. 16, n. 3 p. 69-81, Porto Alegre, 2004. https://doi.org/10.1590/S0102$\underline{71822004000300009}$

MACHADO, Francis Berenger. Dilemas de Mulheres Empreendedoras em Empresas Inovadoras Nascentes. In: Anais do Encontro da ANPAD. 36, Rio de Janeiro, 2012. Disponível em: http://www.anpad.org.br/admin/pdf/2012_GCT1184.pdf. Acesso em: 21 abril 2020.

MARINHO, Emerson; LINHARES, Fabrício; CAMPELO, Guaracyane. Os programas de transferência de renda do governo impactam a pobreza no Brasil? Revista brasileira de economia, v. 65, n. 3, 2011. Disponível em: 
https://www.scielo.br/j/rbe/a/zzrGGrMjQGqTyJq3BNC9VVy/?lang=pt. Acesso em: 03 set. 2021.

MARCONI, Marina de Andrade; LAKATOS, Eva Maria. Fundamentos da Metodologia científica. 8. ed. São Paulo: Ed. Atlas, 2017.

MELO, Marlene Catarina de Oliveira Lopes; LOPES, Ana Lúcia Magri. Empoderamento de mulheres gerentes: a construção de um modelo teórico de análise. Gestão \& PlanejamentoG\&P, v. 13, n. 3, 2013. Disponível em:

https://revistas.unifacs.br/index.php/rgb/article/view/2346. Acesso em: 22 abril 2020.

NATIVIDADE, Daise Rosas da. Empreendedorismo feminino no Brasil: Políticas públicas sob análise. Revista de Administração Pública, v. 43, n. 1, Rio de Janeiro, 2009.

https://doi.org/ 10.1590/S0034-76122009000100011

NOGUEIRA, Conceição. Construcionismo social, discurso e gênero. Psicologia, v. 15, n. 1, 2001. Disponível em: http://www.scielo.mec.pt/scielo.php?script=sci_arttext\&pid=S087420492001000100003. Acesso em: 01 maio 2020.

ONU. Organização das Nações Unidas. ONU Mulheres Entidade das Nações Unidas para a Igualdade de Gênero e Empoderamento das Mulheres. Disponível em: https://nacoesunidas.org/agencia/onumulheres/. Acesso em: 18 abril 2020.

ONU MULHERES BRASIL. Sobre a ONU Mulheres - Garantir os direitos humanos das mulheres no Brasil e no mundo. Disponível em: http://www.onumulheres.org.br/onumulheres/sobre-a-onu-mulheres. Acesso em: 15 abril 2020a.

ONU MULHERES BRASIL. Sebrae se une à ONU para fortalecer empreendedorismo das mulheres. Disponível em: http://www.onumulheres.org.br/noticias/sebrae-se-une-a-onupara-fortalecer-empreendedorismo-das-mulheres. Acesso em: 15 mar. 2020.

PERUCCHI, Juliana; BEIRÃO, Aline Maiochi. Novos Arranjos Familiares: Paternidade, parentalidade e relações de gênero sob o olhar de mulheres chefes de família. Psicologia Clínica, v.19, n. 2, Rio de Janeiro, 2007. https://doi.org/10.1590/S0103-56652007000200005

PINTO JUNIOR, Joelias Silva; SILVESTRO, Anderson Ricardo; ARRUDA, Claudineia Gonçalves de; NASCIMENTO, Antonio Vinicius Fernandes. "Empreende" - Teaching Business Entrepreneurship. Research, Society and Development, [S. 1.], v. 10, n. 13, p. e03101320963, 2021. DOI: 10.33448/rsd-v10i13.20963. Disponível em: https://rsdjournal.org/index.php/rsd/article/view/20963. Acesso em: 5 oct. 2021.

PINTO JUNIOR, Joelias Silva; SILVESTRO, Anderson Ricardo; SCHIRMER, Carlos Miguel Espedito Santos; MUELLER, Eduardo Ribeiro. Formação versus vulnerabilidades: contribuições da educação empreendedora promovida pela Ativa Incubadora de Empresas do IFMT. Research, Society and Development, [S. 1.], v. 10, n. 11, p. e188101119591, 2021. DOI: 10.33448/rsd-v10i11.19591. Disponível em: https://rsdjournal.org/index.php/rsd/article/view/19591. Acesso em: 5 out. 2021a.

ROMANO, Jorge; ANTUNES, Marta. Empoderamento e direitos no combate à pobreza. Rio de Janeiro: ActionAid, 2002. 
SACCHET, Teresa. Capital social, gênero e representação política no Brasil. Opinião Pública, Campinas, SP, v. 15, n. 2, p. 306-332, 2015. Disponível em: https://periodicos.sbu.unicamp.br/ojs/index.php/op/article/view/8641333. Acesso em: 3 set. 2021.

SAMPAIO, Rosana Ferreira; MANCINI, Marisa Cotta. Estudo de revisão sistemática: Uma guia para síntese criteriosa da evidência científica. Revista brasileira de fisioterapia, v.11, n.1, p. 83-89. São Carlos, 2007. https://doi.org/10.1590/S1413-35552007000100013

SARDENBERG, Cecília Maria Bacellar. Conceituando "empoderamento" na perspectiva feminista. 2006. Disponível em: https://repositorio.ufba.br/ri/handle/ri/6848. Acesso em: 03 set. 2021.

SEBRAE (Serviço Brasileiro de Apoio às Micro e Pequenas Empresas). Relatório Especial: Empreendedorismo Feminino. Março de 2019. Disponível em:

https://www.sebrae.com.br/Sebrae/Portal\%20Sebrae/UFs/GO/Sebrae\%20de\%20A\%20a\%20Z Empreendedorismo\%20Feminino\%20no\%20Brasil\%202019 v5.pdf. Acesso em: 30 jun. 2020. 


\section{ANEXo}

\section{Questionário do programa}

1. Conhecia o IFMT antes de realizar o curso aqui?

2. Como ficou sabendo do Curso?

3. Qual a sua idade?

4. Quantos filhos você tem?

5. Quantos filhos com menos de 18 você tem?

6. Você contribui para a renda familiar?

7. Quantas pessoas contribuem para a renda familiar em seu lar?

8. Antes de participar do curso imaginou/sonhou/idealizou abrir algum tipo de negócio? Se sim, qual era?

9. Você participa de programa de transferência de renda (exemplo: bolsa família) ou outro programa de assistência de órgãos do governo ou entidade assistencial?

10. Quando o curso começou você estava?

11. Na escala de 1 a 5, como você avalia o seu conhecimento após as informações recebidas durante a realização do curso?

12. Na escala de 1 a 5 , avalie o seu nível de motivação em relação a continuar um negócio e/ou abrir um negócio na área de formação do curso produzindo e vendendo o que aprendeu.

13. Na escala de 1 a 5 , como você avalia os instrutores/professores do curso ofertado?

14. Na escala de 1 a 5, o quanto se considera apta(o) a aplicar os conhecimentos adquiridos para melhorar a sua renda?

15. Na escala de 1 a 5, como você avalia os produtos e/ou serviços desenvolvidos durante o curso?

16. Você pretende abrir um comércio, atuar como empreendedora autônoma produzindo e vendendo o que aprendeu no curso?

17. O que poderia melhorar no curso?

18. Conte um fato marcante que aconteceu durante o curso. 